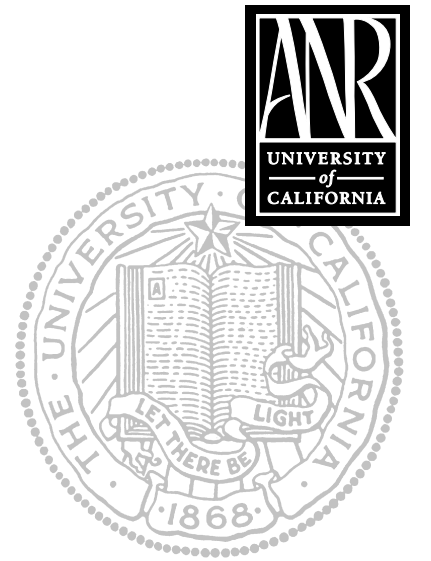

UNIVERSITY OF

CALIFORNIA

Division of Agriculture and Natural Resources

http://anrcatalog.ucdavis.edu

\title{
Establishing Integrated Pest Management Policies and Programs: A Guide for Public Agencies
}

MARY LOUISE FLINT, University of California Statewide Integrated Pest Management Program, UC Davis; SHEILA DAAR, Daar Consulting Group, Berkeley, CA; and RICHARD MOLINAR, University of California Cooperative Extension, Fresno.

\section{INTRODUCTION}

As a result of growing concerns about health and environmental problems associated with pesticides, public agencies are facing increasing demands from their employees, their clientele, and the general public to explain and justify their use of these materials. Agencies must be able to respond with careful, thoughtful answers. Managing insects, plant pathogens, weeds, rodents, and other organisms that become pests is a complex science; applying pesticides safely and effectively in public areas requires substantial expertise and skill. Responses to the public's questions must communicate an understanding of this complexity and a genuine concern for health and environmental problems.

Adoption of a written policy and procedures for making pest management decisions provides an agency with an effective way to respond to the questioning public and at the same time improves the agency's internal decision-making process, resulting in more efficient, more effective, and safer resolution of pest problems. Involving the public and employees in the development and evolution of a pest management policy can help educate everyone on the potential hazards and benefits of pest management practices.

\section{What Is Integrated Pest Management?}

Integrated pest management (IPM) is a pest management strategy that focuses on longterm prevention or suppression of pest problems with minimum impact on human health, the environment, and nontarget organisms. Preferred pest management techniques include encouraging naturally occurring biological control; using alternate plant species or varieties that resist pests; selecting pesticides with a lower toxicity to humans or nontarget organisms; adopting cultivating, pruning, fertilizing, or irrigation practices that reduce pest problems; and changing the habitat to make it incompatible with pest development. Pesticides are used as a last resort when careful monitoring indicates that they are needed according to preestablished guidelines. When treatments are necessary, the least toxic and most target-specific pesticides are chosen.

Implementing an integrated pest management program requires a thorough understanding of pests, their life histories, environmental requirements, and natural enemies, as well as establishment of a regular, systematic program for surveying pests, their damage, and other evidence of their presence.

\section{What Are Special Issues for Public Agencies?}

For many years, integrated pest management programs have been implemented in agricultural cropping systems. IPM programs in schools, parks, and other public places have been a bit slower to be adopted. Public agencies face infrastructure complexities and public relations issues that are not a concern for individual farmers making pest management decisions. 
Pest management programs in public agencies rely on the coordinated activities of many individuals. Often, several different departments and supervisors are involved in activities that affect pest problems and their management. There may be different supervisors for janitorial staff, pesticide application staff, plant maintenance staff, landscape maintenance staff, and landscape design staff-yet all have critical roles in a pest management program. Each group may have different priorities and a different way of doing business; there may not be effective communication between departments. However, these divisional barriers must be broken down and all employees must be enlisted in a program that shares common goals and approaches to achieve success.

In addition, public agencies must be accountable and responsive to the public. People in the community often want justification for the use of certain types of pesticides and at the same time may demand to know why the agency isn't doing a better job of controlling organisms that they consider pests. A written IPM policy enhances an agency's ability to respond to public concerns and coordinate activities within its bureaucracy.

\section{What Will an Integrated Pest Management Policy Do for Your Agency?}

Although the initial reason for developing an integrated pest management policy may be to explain and justify your agency's use or nonuse of pesticides, it will provide many other benefits as well. For instance, a written policy provides procedural guidelines for the agency. There are many federal, state, and local regulations that must be followed when storing, transporting, applying, and disposing of pesticides, and there are specific laws regarding who can recommend pesticides and how applicators must be trained in California. Specific safety equipment and procedures are required for the use of many pesticides. A written policy assures that these laws and regulations are adhered to each time a pesticide is used and helps you document that proper procedures were followed.

Developing and establishing a set policy educates applicators, administrators, other employees, and the general public about when and why pesticides are used and when alternative methods might be adopted. It also helps employees gain a better understanding of their jobs. An IPM policy may reduce your agency's reliance on pesticides, protect the environment, and protect applicators, coworkers, their families, and the public. If problems do arise, the policy provides procedures for immediately handling the problem and helps you to document that your agency acted responsibly.

\section{SETTING POLICY GOALS}

The first step in establishing an integrated pest management policy is to determine the goals of your pest management program. Policy goals give your agency a framework on which to base individual decisions. All goals may not be met with each and every decision, but established goals will give your agency a set of priorities to work from. Goals will vary considerably from agency to agency according to the function of the agency, public and wildlife access to agency grounds, employee concerns, and political priorities. The overall goal for many agencies would be "to establish a more effective and safe pest management program"; however, this type of general goal is not specific enough to guide decision making. More specific goals might be divided into two categories: political, educational, and public relations goals for policy makers; and operational goals for basing individual pest control decisions. 
Goals should be set with input from employees and the general public. Establishing goals is one of the most productive ways that people without technical expertise can participate in the policy-making process. Involving various factions of the community in policy development is a good way to garner widespread support for the program and policy later on. Pest management policy goals differ with the function of different agencies; examples of possible goals follow.

\section{Examples of Political-Educational Goals}

- Encourage employees to first consider alternatives to pesticides.

- Keep citizen complaints at or below current levels through effective practices and public education.

\section{Examples of Operational Goals}

- Design a written plan for implementing IPM procedures throughout the facility and for individual pests.

- Ensure that the public agency's governing board (supervisors, trustees, directors) is kept informed as to the progress of the IPM program. The board's support and encouragement can assure the program's presence and fiscal health.

- Establish procedures (e.g., through a technical review committee and periodic reevaluations) for assuring that the latest information is incorporated into pest management decisions.

- Develop procedures for allowing public input without disruption of the overall program.

- Make information accessible to the public and employees regarding pesticides used and areas treated.

- Ensure that applicators are educated regarding current pesticides, their hazards, and applications.

- Educate employees and the public about pest management problems and solutions.

- Develop protocols for plant inventory and pest problem survey.

- Establish monitoring programs and evaluative criteria to measure control success.

- Maintain pests at levels that prevent them from becoming a health hazard.

- Eliminate fire hazards (such as tall dry grass or dead trees) in a timely manner.

- Reduce or eliminate all use of pesticides in CDFA category I, II, or III (agency choice).

- Establish and maintain pesticide use reporting and recordkeeping.

- Provide employees with pest management training, including diagnostic skills and use of alternative pest control methods.

- Establish and maintain records of pest occurrence and levels at which they become a problem.

- Identify and evaluate cultural and environmental conditions on the grounds that seem to encourage pest problems.

- Use the safest effective practices whenever economically feasible. 


\section{PROCEDURES FOR DESIGNING AN IPM PROGRAM}

Once policy goals are set, persons with pest management expertise within (and perhaps also outside) your agency must establish reasonable procedures for meeting these goals. At first, some operating guidelines will be crude, but you can refine them with time as your experience grows. However, it is important to have established procedures so you can document and measure their success and improve them with time. The procedures listed below are intentionally generic because of the great variety of pest management situations. Pest control procedures must be developed on a pest-bypest basis, and procedures will change and evolve over time. You can get help by consulting the resources at the end of this publication, talking with University of California Cooperative Extension staff, consulting private pest management consultants, or talking with other agencies with similar problems. Remember to keep your policy goals in the forefront and to regularly document and reevaluate your program. Keep up with new ideas and practices through continuing education and professional publications.

The success and sophistication of your IPM program will depend on the experience, skill, education, and enthusiasm of your employees. Take these factors into account when establishing procedures. Don't expect employees to perform new tasks without encouragement and training. You may need to bring in outside expertise to assist in the first season of a new program. Expect to implement change over time, incorporating a few major component at a time.

\section{Step-by-Step Procedures for Developing an IPM Program}

1. Identify all potential pests (including all life stages) in the system. Verify damage symptoms associated with pests and identify natural enemies. For plant pests, this will require identifying plant species in the management area and developing pest lists for each host. Train all pest management personnel to accurately identify beneficials as well as major pests and their damage, and to seek help when they can't make a conclusive identification. Have materials (e.g., a field manual or identification texts such as those listed in the resources on p.11) and tools (e.g., a dissecting microscope and hand lens) available to assist in pest identification. Make provision for identifying new pests as they are observed (see step 9).

2. For each pest, establish monitoring guidelines. These may be crude at first but can be improved with experience. Monitoring methods vary from pest to pest (for more information, see the resources on p.11), but all involve regular (e.g., weekly) checking, visually or with traps, for pests or damage symptoms, or other evidence of pest presence (e.g., feces); methods also involve some way of quantifying observations. Also provide for monitoring of beneficials and natural enemies. Overall, the objectives of a monitoring program are to pinpoint precisely when and where pest problems may become intolerable and to determine the effectiveness of treatment actions. To determine the need for treatment, the objectives must be used with action thresholds, as discussed in step 3.

3. Establish injury levels and action thresholds for each individual pest species before making any treatment. An injury level is the pest population size (e.g., 10 aphids per leaf or 2 cockroaches per trap) that is associated with intolerable damage. Action thresholds are the set of conditions required to trigger a control action-usually a pesticide application. 
Determine the infestation levels that will be intolerable to people or to structures or that will cause unacceptable damage at various times of the year, plant growth stages, situations, and so on. At the same time, devise a monitoring plan for detecting these pest levels and determining when to treat. Over time you will refine the injury levels and action thresholds; however, treatment is usually required when

- a regular monitoring program indicates that the pest population will reach the injury level if left untreated; and

- biological or environmental factors cannot be expected to reduce the pest problem within a reasonable time; and

- treatment cost and health and environmental hazards are considered less than the potential pest damage.

4. Establish a recordkeeping system. Good records are essential for evaluating and improving your IPM program and for reference when the public wants to know how you handle certain types of pests. Any recordkeeping system should include observations such as

- identity of the pest (to species if possible) and how the identification was made

- the size (density) of the pest infestation

- the geographic distribution of the pest problem in the managed area (a map of your facility can be useful for this)

- complete information on how you treated the problem, including what, how much, where, when, who, cost, application difficulties, and the effectiveness of treatment in solving the pest problem (short-term and long-term)

- the side effects of the treatment on nontarget species

- public complaints or other problems that arise, and positive feedback

5. Develop a list of acceptable management strategies for each pest. The preferred methods in an IPM program prevent pest problems and therefore eliminate the need for pesticide applications. These methods might include modifying structures or landscaping to be less conducive to pest survival, using pest-tolerant or pest-resistant cultivars, using cultural practices (such as mulches or mowing and the use of pruning and planting times that discourage pests), and educating the public to be more tolerant of pests. Encouragement of naturally occurring biological controls can be very important; in some cases, barriers, traps, or mechanical removal can be effective. Develop a list of pesticides that are effective against each pest but are least disruptive to the environment-for instance, soap sprays, microbials, botanicals, oils, and synthetic pesticides with low LD-50 and short persistence. Investigate and document the potential for using low rates, spot treatments, and other selective ways to integrate pesticides into an IPM program that is least disruptive to biological control agents and nontarget organisms. For instance, using bait stations or other formulations that reduce exposure to humans or nontarget organisms is an important way to reduce potential risks. 
6. Develop specific criteria for selection of pest management methods. Make the criteria known to employees and the public. Although all criteria may not be met in every case, choices should meet the majority of the following requirements:

- least disruptive of natural controls

- least hazardous to human health

- least toxic to nontarget organisms and least damaging to the general environment

- most likely to produce permanent reduction of the pest

- easiest to carry out effectively

- most cost-effective in the short- and long-term

For instance, avoid the common practice of regularly scheduled perimeter sprays to keep invading species such as ants, beetles, spiders, or earwigs out of buildings. This strategy does not provide a long-term solution to a problem and may kill beneficials and promote pesticide resistance. Structural changes, habitat reduction around buildings, and the use of baits can provide long-term control in many cases.

7. Develop guidelines to be followed each time a pesticide is used. Prepare a checklist to be used each time an application is made. Important items on the checklist should include:

- choosing the safest material that is effective

- considering label signal words, persistence, impact on nontargets, and potential chronic human health effects

- considering the potential for treating only the most seriously infested areas (i.e., spot treatments) to allow for survival of natural enemies (this works for some insects and mites only)

- making sure the pesticide is registered in California for the situation and that you are aware of all laws regarding its use

- if required, making sure you have in hand a written recommendation for using the pesticide made by a licensed pest control adviser

- checking the pesticide label to make sure all precautions and legal requirements are being carefully adhered to

- making sure all safety equipment and clothing are used

- verifying that the person doing the application is certified and qualified to handle the equipment and material chosen and that the person has been adequately trained

- after the application, monitoring the pest population to see if the treatment was effective

- keeping written records

- obtaining the Material Safety Data Sheet (MSDS) for the pesticide from the manufacturer

- making sure your application equipment is appropriate for the job and calibrated

- being prepared for all emergencies and knowing whom to call for help and interim measures to take before help arrives 
8. Designate a person to be responsible for each step along the way. These are the people (e.g., job titles) who will be responsible for making decisions, carrying out the various pest management and emergency operations described in your policy, and regularly evaluating the effectiveness of the program.

9. Develop a list of resources. Know where you can go when information or outside help is needed. Include resources for pest identification, pesticide recommendations, and information about pesticides, pest management, and handling emergencies. Build a library and have employees participate in training and continuing education programs on a regular basis. (See the resources on p.11.)

10. Consider your IPM policy to be a "living document" that changes as you acquire experience and new information. Establish an oversight committee that includes persons with toxicological and pest management expertise to assist with initial review of procedures and future changes in the policy. Review the program regularly (e.g., annually). Involve environmental organizations, worker health advocates, and other interested members of the public or employee representatives from your facility in the development and revision of the IPM policy.

\section{Outside Contractors}

Some agencies have no staff or limited staff to devote to pest management activities. Some do not have staff with expertise or appropriate licenses to carry out certain pest management activities. In these cases, agencies will want to hire outside contractors for pest management services.

Contractors differ in their skills and experience, and it is important to hire a company that is reliable and knowledgeable about IPM practices and the goals of your IPM program. Performing appropriate preventive and monitoring activities may take extra time, so the lowest bidder may not always be the best company for your job. Be sure to specify needed IPM practices clearly in your contract and formalize a good communication system. Hire contractors who have appropriate pesticide application and pest control adviser licenses and training and who also have experience in IPM in situations such as yours. Ask them to provide you with their license number.

The first step in hiring a contractor is to prepare a request for qualifications (RFQ) that will allow you to prescreen and ensure that only qualified contractors submit proposals for the bid process. Next, prepare a request for proposals (RFP) that details the terms of your IPM policy. Evaluate the responses to the RFP according to the contractor's ability to meet the goals of your program. As part of the pest management contract, develop a quality assurance form (QAF). The QAF is filled out by the contractor each time a service is provided. It should detail information on pest sightings, sanitation and structural concerns, pesticides applied, traps or monitoring stations installed, pesticide use or other regulatory forms filed, and any additional pest management concerns.

\section{BUILDING SUPPORT FOR YOUR IPM PROGRAM WITHIN AND OUTSIDE YOUR AGENCY}

Once an IPM policy has been adopted by a city council, school board, or other policymaking body, it falls to agency staff or pest control contractors to implement the policy. Change never comes easily. There are a number of predictable obstacles within an agency—both psychological and institutional—to be overcome when initiating IPM programs. At the same time, even if the public has been involved with development of a policy, there are likely to be occasional complaints and controversies, especially as pests, pest control practices, and public concerns change. 


\section{Psychological Barriers to IPM Adoption}

\section{Psychological resistance to change}

The problem: When pest control personnel are asked to make pest management decisions in a new way and to use new methods, they may feel that there is a negative implication regarding their past performance.

How to address it: Many factors contribute to the need to change pest management practices. Most of these factors are beyond the control of the individual pest manager. They include loss of effectiveness of many pesticides as pests develop genetic resistance; increased availability of less-toxic products or techniques; increased requirements for documentation, licensing, certification, and continuing education; and public concern about adverse health and environmental effects of pesticides. Adoption of IPM methods enables pest control professionals to respond to these forces for change and at the same time achieve cost-effective control of pests.

\section{Loss of authority}

The problem: Adopting an IPM approach may engender fear of many kinds of losses, including loss of personal authority or supervisory authority. In the first case, individuals may fear that their experience in the field will become devalued, particularly if their expertise has been in pesticide application. In the second case, supervisors may fear that the system will become more efficient and they will lose positions.

How to address it: Successful IPM implementation enhances both personal and supervisory authority. Many of the new, less-toxic pest control materials such as pheromones, microbial and botanical pesticides, insect growth regulators, and biological controls require application skills and equipment that are similar to conventional pesticides, and workers can readily learn necessary modifications to conventional practices. Mastery of IPM monitoring skills enhances the professionalization of pest management and can lead to upgrading job classifications. In terms of supervisory authority, IPM programs provide managers with greater decision-making responsibilities and an increase in the flexibility of staff assignments. For example, by emphasizing monitoring rather than prophylactic pesticide applications, staff time previously spent spraying can be redirected to other tasks, increasing overall productivity within a department.

\section{Imagined difficulty in learning new technology}

The problem: The techniques used in IPM may initially appear to require conceptual and operational skills beyond those of current staff.

How to address it: This fear can be overcome by building staff training into the IPM implementation program and by establishing a transition period during which pest management personnel experiment with and fine-tune IPM methods. Transition new practices in a step-by-step fashion so that not all changes are made at once.

\section{Fear of IPM program failure}

The problem: Supervisory personnel may believe that the IPM program will not work for them even though it has been successful for a nearby agency.

How to address it: IPM programs are specifically designed for the particular circumstances of each location, such as the plants and pests involved, microclimates at the site, and management history. While the IPM decision-making process remains the same no matter what the pest or site, the tactics and products used may vary greatly from one location or circumstance to another. This flexibility usually assures an appropriate solution to the pest problem. 


\section{Institutional Barriers to IPM Adoption}

\section{Fear that IPM means no access to pesticides}

The problem: Some people think that IPM means never using chemical controls.

How to address it: While IPM definitely encourages alternatives to pesticides when feasible, chemical controls are used when necessary. However, in an IPM program, pesticides that are least disruptive, most selective to specific pests, and rapidly biodegradable are preferred over common, broad-spectrum materials. For instance, the microbial insecticide Bacillus thuringiensis, a naturally occurring bacteria that kills only certain groups of pest insects, is an example of the type of pesticide preferred for use in IPM programs. When chemical controls are used in an IPM program, every effort is made to reduce human and nontarget exposure, for instance, by putting materials in bait stations or within walls or by "spot-treating" specific areas rather than broadcast spraying.

\section{Fear that IPM is more expensive than traditional pest control}

The problem: Until agencies have experience with IPM, they may expect that it will cost more than their current program.

How to address it: While there are short-term start-up costs for any new technology, in the long run IPM has often proven to be more cost-effective than a strictly chemical control program. When possible, IPM programs substitute information gathering (monitoring) in place of other pest control activities. This can be very cost-effective. For example, by monitoring the 1,100 elm trees in their city rather than prophylactically spraying them against elm leaf beetles, the city of San Rafael, California, found that only a small portion of the trees required treatment. As a result, the city saved $\$ 1,400$ (including costs of monitoring) in the first year of its IPM program compared to the previous year when all trees were sprayed.

Also, IPM methods emphasize reducing the source of pest problems (e.g., eliminating pest habitat and food sources) rather than treating the pests themselves (e.g., spraying). This type of pest prevention program is more cost-effective than a continuing program of pest reduction that does not address the underlying cause of the infestation. For example, by permanently reducing habitats for rats (i.e., by filling rat holes with concrete, changing the design of garbage cans, and increasing frequency of garbage pickup), the National Park Service was able to permanently reduce rat populations in certain parks. Previous rat control programs that had relied on poison baits had not been successful despite large expenditures of labor and money.

\section{Lack of in-house IPM expertise}

The problem: Agency staff may be unfamiliar with IPM and not know where to go for information.

How to address it: While it is true that IPM education and training resources are not as widely available as those for chemical controls alone, good resources can be found in any community. Many agencies have found it feasible to hire an IPM specialist to work as a consultant to in-house pest control staff during the initial year or two of IPM implementation, or to create an IPM coordinator position and recruit nationwide. Increasingly, cooperative extension advisors or agents, college horticultural or entomological faculty, pest control advisers, and a nationwide network of nonprofit organizations involved in pest management, sustainable agriculture, and environmental protection are able to provide IPM information and advice. Periodicals and Web sites providing practical technical advice on IPM methods for specific pest problems are increasingly available. The resources at the end of this publication will assist anyone attempting to implement IPM programs. 


\section{SOME FINAL HINTS FOR IMPLEMENTING AN IPM PROGRAM}

The following suggestions will help overcome barriers and smooth the transition to IPM implementation.

Mandate staff training in IPM. When writing the IPM policy document, include a requirement for the continuing education of pest management personnel. Ensure that budgetary allocations are made to assist them in obtaining the information, skills, and equipment they need to carry out the policy.

Start small. Begin IPM implementation in one location (e.g., one lawn in one park; one kitchen in one school) and include short-term objectives. For example, when dealing with a number of pest problems, identify one of the pests likely to respond quickly to an IPM approach so that a short-term objective can be realized. Test the IPM methods and fine-tune them. When the program is working successfully in one area or against one pest, expand the program.

Don't change everything at once. To the maximum degree possible, retain communication and accountability procedures already in use. Tailor new recordkeeping and reporting forms to fit existing agency formats. Recycle existing equipment to uses consistent with IPM methods rather than immediately eliminating the equipment.

Share the process. Involve all pest management personnel in the day-to-day IPM program process as early as possible so that they will understand and support the program during the sometimes difficult transition period.

Emphasize communication and plan for future training. During the IPM transition period, keep all personnel informed about what is planned, what is happening now, the expected outcome, and what will happen next. Prepare written records and visual aids that will remain in the agency when persons associated with development of the IPM program are no longer there.

Build in a reward system. Identify benchmark objectives (e.g., testing of mechanical weed control methods in one park during a 3-month period or a 10 percent reduction in pesticide use in the first year). Encourage staff to achieve objectives (e.g., a letter of commendation from agency head, recognition at an awards ceremony, an article in an agency bulletin, merit pay increase).

Publicize the program. Develop good rapport with agency public relations personnel and with the local news media. Include field and management staff at photo and interview sessions about the IPM program.

Involve the community. Form an IPM advisory committee composed of interested organizations, members of the public, and pest control professionals. They can help make IPM implementation a budgetary priority in the agency, can donate or locate resources that may not otherwise be available to the agency, and may add needed expertise and experience to the process. 


\section{RESOURCES FOR AGENCIES DEVELOPING IPM POLICIES}

\section{General Information}

In addition to the resources listed in this section, other agencies that deal with problems similar to yours, as well as pest management consultants, can be valuable sources of general information.

The University of California County Cooperative Extension offices are a valuable resource. In California, check your phone book under University of California or Cooperative Extension; or, see the University of California Agriculture and Natural Resources Web site, http://ucanr.org/.

\section{Professional Organizations}

- Association of Applied IPM Ecologists (AAIE) http://aaie.net/

- California Agricultural Production Consultants Association (CAPCA) http://www.capca.com/

- California Weed Science Society (CWSS) http://www.cwss.org/

- Pesticide Applicators Professional Association (PAPA) http://www.papaseminars.com/

\section{Web Sites}

The University of California Statewide IPM Program Web site at http://www.ipm.ucdavis.edu has information on managing and identifying pests of landscape, structures, agricultural crops, and pests of medical importance. There are links to pages related to pesticide toxicity, water quality, and other related resources.

The California Department of Pesticide Regulation IPM for Schools Web page at http://www.schoolipm.info/ has complete information on California's IPM in Schools Program as well as links to other information relating to managing pests in public buildings and landscapes.

The U.S. EPA Region 9 has an IPM manual for schools, Integrated Pest Management for Schools: A How-to Manual on its Web site http://www.epa.gov/region09/toxic/pest/school/. The manual includes appendixes that include IPM contract performance specifications and sample monitoring forms.

Many (but not all) pesticide Material Safety Data Sheets (MSDS) and labels are available at the Crop Data Management Systems Web site:

http://www.cdms.net/manuf/manuf.asp

Other useful Web sites related to pesticides include:

- National Pesticide Information Center http://npic.orst.edu/links.htm

- Extoxnet (Extension Toxicology Network) http://ace.orst.edu/info/extoxnet/ghindex.html

- U.S. EPA Reregistration Fact Sheets http://www.epa.gov/pesticides/ 


\section{Books and Other Literature}

A free catalog is available from University of California Agriculture and Natural Resources Communication Services (6701 San Pablo Avenue, Oakland, CA 946081239; http://anrcatalog.ucdavis.edu; phone 1-800-994-8849/510-642-2431) that lists many publications of value in managing pests, including those listed below as University of California ANR publications.

Dreistadt, S. H. 1994. Pests of landscape trees and shrubs: An integrated pest management guide. University of California ANR Publication 3359.

Flint, M. L. 1998. Pests of the garden and small farm: A grower's guide to using less pesticides. 2nd ed. University of California ANR Publication 3332.

Flint, M. L., and P. Gouveia. 2001. IPM in practice: Principles and methods of integrated pest management. University of California ANR Publication 3418.

Mallis, A. 1997. Handbook of pest control. 8th ed. Cleveland, OH: Mallis Handbook and Technical Training Company.

Marer, P. J. 1991. Residential, industrial, and institutional pest control. University of California ANR Publication 3334.

O'Connor-Marer, P. J. 2001. The safe and effective use of pesticides. 2nd ed. University of California ANR Publication 3324.

Salmon, T. P., and R. E. Lickliter. 1984. Wildlife pest control around gardens and homes. University of California ANR Publication 21385.

Whitson, T. D., L. C. Burrill, S. A. Dewey, D. W. Cudney, B. E. Nelson, R. D. Lee, and R. Parker. 2001. Weeds of the west. 9th ed. Western Society of Weed Science. Available from UC ANR Communication Services as Publication 3350.

Zavala, M. 1991. The illustrated guide to pesticide safety/ Guía ilustrada para el uso seguro de pesticidas. Instructor's Edition. University of California ANR Publication 21489. 


\section{FOR MORE INFORMATION}

Visit our online catalog at http://anrcatalog.ucdavis.edu. You can also place orders by mail, phone, or fax, or request a printed catalog of publications, slide sets, videos, and CD-ROMs from

University of California

Agriculture and Natural Resources

Communication Services

6701 San Pablo Avenue, 2nd Floor

Oakland, California 94608-1239

Telephone: (800) 994-8849 or (510) 642-2431

FAX: (510) 643-5470

E-mail inquiries: danrcs@ucdavis.edu

An electronic version of this publication is available on the DANR Communication Services Web site at http://anrcatalog.ucdavis.edu.

\section{Publication 8093}

(C) 2003 by the Regents of the University of California, Division of Agriculture and Natural Resources. All rights reserved.

The University of California prohibits discrimination against or harassment of any person employed by or seeking employment with the University on the basis of race, color, national origin, religion, sex, physical or mental disability, medical condition (cancer-related or genetic characteristics), ancestry, marital status, age, sexual orientation, citizenship, or status as a covered veteran (special disabled veteran, Vietnam-era veteran or any other veteran who served on active duty during a war or in a campaign or expedition for which a campaign badge has been authorized). University Policy is intended to be consistent with the provisions of applicable State and Federal laws.

Inquiries regarding the University's nondiscrimination policies may be directed to the Affirmative Action/Staff Personnel Services Director, University of California, Agriculture and Natural Resources, 300 Lakeside Drive, 6th floor, Oakland, CA 94612-3550; (510) 987-0096. For information about downloading this publication, telephone (530) 754-5112. For information on obtaining this publication, call (800) 994-8849.

To simplify information, trade names of products have been used. No endorsement of named or illustrated products is intended, nor is criticism implied of similar products that are not mentioned or illustrated.

pr-01/03-SB/VFG

ISBN 978-1-60107-267-2

\section{UEER REVIEWED}

This publication has been anonymously peer reviewed for technical accuracy by University of California scientists and other qualified professionals. This review process was managed by the ANR Associate Editor for Human and Community Development. 